\title{
Bongitude and the Specification of Freedom
}

\author{
Probal Dasgupta*
}

\section{Abstract}

Both swaraj and swadeshi emerged in the context of nationalist discourses that set independence as a universal goal. This notion of independence derived its meaning from the empires that co-constituted modernity, and meant decolonisation. Despite metaphors and other extensions, the little nationalisms within the Indian transnation have proved unable to postulate any sort of semisovereignty within the larger republic as a credible goal. This Bengal-focused study argues that sustainable autonomy cannot be promoted if all sub-nations are stampeded into 'one size fits all'. Any ethnic community must take exonyms like 'Bong' on board and learn how to elude ethnographic museumisation, how to fashion an explicitly contested interdependence with other stakeholders in a game of history that must go on even after the old nationalisms have crumbled. This paper's interpretive methodology affirms the idiographic level, resists multiplying nomothetic moves beyond necessity, and targets positivism.

Keywords: Transnation, Indianisms, Bongitude, Swaraj

\section{Introduction}

Bargohain (2014), writing for a Kolkata periodical and aware of the fact that his text will be translated into Bangla, narrates two

\footnotetext{
* Indian Statistical Institute, Kolkata, India; probal.dasgupta@gmail.com
} 
anecdotes, in the context of setting forth briefly the impressions of Bengalis that he has received over the years as a creative writer in Assamese.

His first anecdote is about getting stranded at a railway station in Delhi in the middle of the night, running into a companionable Delhi-based young man from Bengal who is going to spend the night in the waiting room anyway, and feeling grateful for his unsolicited, hospitable company. Bargohain's second anecdote is set in Puri. Among the delegates at a literature seminar, Bargohain is the only Assamese present. A prominent Bengali lady asks Sunil Gangopadhyay to introduce her to him. Sunil obliges: "This is Homen Bargohain," he says. "He is this year's Sahitya Akademi prize-winner. I really need to tell you something else about him. His reading in Bangla literature is stupendous - he must have read a lot more than you or me." She tries to say something pleasant, and comes up with: "Oh I see, it must be this massive reading in Bangla that made his Sahitya Akademi award possible." A split second later, she realizes how that sounded, and exclaims: "What an awful thing to say! Please do forgive me." Bargohain tells us that he was not offended or hurt, but that if one is dealing with a Bengali, one has to switch on one's maximum generosity, one has to be ready for this self-centred streak in the Bengali personality. This streak, he observes, shows up quite often even in such a person as this lady, who became a close friend of his in later years and who is one of the most cosmopolitan persons he has ever met. Bargohain concludes that precisely this open-heartedness that makes the typical Bengali so friendly and attractive to others also keeps on candid display an unbridled ethnic ego that systematically offends.

One reason for highlighting Bargohain's second anecdote is that it features Sunil Gangopadhyay, who was openly touchy about the Anglophone Indian habit of calling Bengalis Bongs - and who must have also been distressed by the epithets Gujus, Sirds, Tambrahms and so on. Pace Gangopadhyay, I am afraid we in India cannot afford to treat as an epiphenomenon these Anglophone Indians, the big time users of ethnic labels like Bong. I propose that we should label these Anglophones as Angs. In contrast to the hasty and unexamined reactions that seem to satisfy the average Ang 
imagination, we who care for the future should take a long-term view; hence the toy word Bongitude.

I have suggested elsewhere that India's Angs are unable to provide leadership because their authority is constantly undermined by Anglo-American masters whose cultural resources they regularly import. In this paper I argue that the rest of us, however, have to keep doing business with stereotype-laden Angs, as part of the enterprise of making sense as constituents of an unusual transnation called India. We take their mockery on board, then, as part of the way we make history, the contemporary Indian way that we have not yet been able to articulate as a self-respecting style. For example, Bongs accept 'Bongitude' as a half-understood point of departure, initiating a journey that one hopes will project some meaningful telos, as we all keep travelling.

"For example," I just said; exactly what do we have in mind when we showcase Bongs as an example of an ethnicity participating in the Indian transnation? Exactly what does Bargohain have in mind when he writes - and I italicise the part I am asking about - "It is impossible to disagree with the proposition that literature in Bangla is far ahead of Assamese (although I do not have such a high opinion of contemporary Bangla writing in particular), but does that give anyone the right to overtly glorify their own community and hit others below the belt?" In his remarks on the lady who spoke abrasively, Bargohain assures us that she is cosmopolitan; what is at stake in this endorsement?

In a fuller exposition, I would have had the space to unpack these questions slowly and arrive at a methodological position. Alas, space constraints force me to be dogmatic. I hasten to announce that I advocate an interpretive methodology that affirms the idiographic level as valuable, resists multiplying nomothetic moves beyond necessity, and specifically targets positivism for reasons of principle. I shall argue that the Bengali journey cannot be from a stereotypical Bongitude defined by others to an authentic Bengaliness defined by some ethnically pure collective selfposition; that too would be a higher-order stereotype in action. The bureaucratic proposal to impose one model of subnationhood all over the great Indian nation is thoughtless and unimplementable. Every ethnicity is different. This heterogeneity renders impossible 
the one-style-fits-all model Bargohain's remarks suggest - an impossibility we should welcome, for we need to move out of ethnography and into a frankly heterogeneous history-making that involves many and various stakeholders.

My argument assumes that the context in which we hold these discussions is an India that we visualise as a transnation even though our explicit codifications do not acknowledge the fact that we do so. Here is a tentative ten-point unpacking of the idea of India as a transnation:

1) A transnation rests on an explicit recognition of discursive multiplicity and on a republic-constitutive use of translation.

2) In India's case, the translation traffic privileges English and Hindi differently: only English texts are treated as definitive, and only English serves as a medium for bridge translation.

3) The subcommunity of Indians identified as Englishproficient, required by statutory reference groups to demonstrate that English comes 'naturally' to them, edit their careful speech and writing with metropolitan (British and American) norms in mind; the resulting naturalness effect is a cultivated deshabille, along the lines of frayed jeans. Their editing leaves some signature Indianisms intact for the sake of Brand India. Such naturalising practices make our 'Angs' comfortable, but obstruct the republic's constitutive enterprise of translation and interpretation. When we fall for the cultivated deshabille effect, we confuse the play of product branding with the work of perfecting our processes.

4) The constitutive enterprise of translation and interpretation is continuous with the teaching of English as a VLFT - a Vehicular Language of 'Formalised Transactions' (ranging from science and industry through commerce to, well, the 'smiles and snores' of protracted juridical negotiation among nations). Teasing the strands of the playgroundbound play of Ang individualism from the architectural labour of these transactions and transmissions is a crucial 
step we have been getting better at in practice. On our way to a proper understanding of its conceptual importance in the India Process, we need to map theoretically the interfaces between industrial English and pedagogical English.

5) We may map them in terms of a hermeneutics of mediation, of which translation and teaching are special cases, and for which the regional discourses in local languages become permanent contextualisers, in the sense that they shape and systematically overflow the representative codification claims made by domestic and metropolitan Anglophones who write on their behalf.

6) The transactions envisaged at point (5) can be upscaled if we find ways to formally acknowledge the necessary artificiality of all representation arrangements - our only viable strategy for dealing with the fact that industrial English is an objectified notation masquerading as a human language capable of subjectivity. Conversations transacted in English constantly run the risk of the industrial hijack of the cognitive; the contagion of this risk also targets nonEnglish discourses held captive by English keywords.

7) Simon (2006) pits the statist ideology and consequent nomothetic methodology of its diegesis against an idiographic counterpoint - her ideal-type-based handling of "episodes in the life of a divided city", Montreal. Learning from both wings of her endeavour and from Bleich's (1988) countervertical strategies, we can institute an interdiscursive practice that deploys the metalinguistic tools of amphiglossia - formal on the vertical discourse reception axis and substantive on the horizontal episode relay axis towards a composite telos. The point is to anchor this practice in the agency of regional, interlocal stakeholders who use cisnational tools in order to visualise a civilisational metaconversation. To visualise this is to hope to turn the interethnic crises of today into sustainable and permanently enlightening dynamics - to hope to replace wars with peaceful games. 
8) At the level of translating and transmitting, a democratic approach cultivates both the vertical axis affirming the republic's sovereignty and the horizontal axis of deliberation. On the horizontal axis, consultative deliberation, which must take place at the pleasure of the people, involves producing user-friendly versions or exegeses of all the key texts. These pedagogic rewrites meet the different needs of extremely diverse users, enabling them to provide feedback. The challenge is to find ways for the system to accept and implement such feedback. Justice must not only be done; it must be seen to be done.

9) Under proceduralist approaches to democracy and justice prompted by the fear of partisan bias - theorists in general, and architects of modern India in particular, have tended to promote uncritical positivism (by which I mean blind reliance on putative 'science' as an adjudicator) as a counterpoint to constitutionally guaranteed 'religious freedom'. A transnation can guard against the risks of this policy by fully integrating 'science' into the pedagogic chain of translation/ transmission, forcing the putatively nonnegotiable outcomes of 'research' to seek public contextualisation as part of their validation cycle.

10) These moves open up theoretical and practical questions as to how best to formulate and pursue the transnation's negotiated plurality goals under a broad construal of 'maximal localism' (called the 'subsidiarity principle' in Europe; it insists that every issue be addressed at the lowest level possible, in the pyramid that takes us from the village to the transnation).

As we move through these ten points, the stereotypical question of pedagogy, seen vertically in the context of educational business as usual, gives way to a composite, situated question at which pedagogy intersects with translation in real time, with the concrete interests of citizens in mind. Such recontextualising opens up an issue that we propose to call the 'collective ZPD issue'.

To be sure, this wording invokes Vygotsky's (1986) notion of Zone of Proximal Development as one point of departure. But the point 
is to combine it with Ghosh's (1993) suggestion, inspired by Tagore, that the quest for social justice should take a situated form focused on balance, rhythm, symmetry as performative dimensions informing social action. Ghosh is concerned about the conceptual growth of individuals in real time, with these priorities in mind, in dialogue with a demographically fair cross-section of significant others. Cross-breeding Vygotsky with Ghosh, I would like to suggest, leads us to the visualisation we want; what comes into view is a sustainable interactive basis for local and regional autonomy. The process we visualise enables these interacting individuals to converge on a collective $\mathrm{ZPD}$. This convergence on the practical plane underwrites its emergence on the conceptual plane -- cutting the red tape that otherwise separates reasonable milieux from rational structures. Here we invoke Ganguly (1978) on rational vs reasonable and Mills (1959) on the milieu/ structure binary.

These proposals are formally cognate to the valorisation, in Dasgupta (2016), of the theatrical aspect of all performance and the to-and-fro character of dialogue, especially the asking and answering of questions. In that text, however, I was not concerned, as I am in this paper, with a pursuit of dialogue oriented to the goal of socially balanced communication and a mode of collective growth.

Central to the present paper is the following translation-theoretic characterisation of autonomy as a telos: Autonomy is the collective ability to sponsor the continuous individual production of valid novelty in thought and action. The pursuit of autonomy requires real-time democratic monitoring of scientific inquiry; a transnation is too big to handle this monitoring all by itself; maximal localism must apply for reasons of principle. In this process it becomes necessary to resist positivism, which, in league with the standard parameters of anti-green industriality, tends to entrench empire and slavery. Among alternatives to positivism, the specifically idiographic pursuit of these goals adds a public accountability filter to what otherwise looks like a first draft of scientific work. This filter, which raises the bar for what shall count as a valid claim for 'serious science' status, is motivated (Dasgupta, 2000) by the intimate connection between exposition, translation and pedagogy. 
The structuralist error, which usually takes the form of reading a name and postal address as a pyramid -- John Doe, 1617 Flowery Street, Littleton, Creeper District, Riverine State, Monsoonland, Asia, etc. -- invites us not just to parse Monsoonland as a republic and Riverine State as a constituent state, but to construe every item on that list as a state in principle, regardless of size. The individual then becomes a one-person state impatiently waiting for a chance to secede from the boring company of stupid others. There are variants of this ubiquitous state model that look Hegelian and hug the contemporary ground very closely indeed. When you concede that redrawing maps will cost wars and negotiations that are either abhorrent or unaffordable, you settle for cultural wars that look cheaper, and you begin to ask for multicultural and other sponsorships. Consequently, the multikulti welfare state even grants its little quasi-state vassals a little bit of plurally-tailored autonomy, perhaps in the form of pocket money to celebrate a Durga Puja or an Eid-ul-Fitr in Berlin or Ottawa.

But even this, however attractive it may look to some variant of the post-nationalist imaginary, is still within the structuralist error; it is still the classical state apparatus speaking; in all its gestures and those it sponsors, that machine practices nothing but nomothetic imitations of the appearance of scientific inquiry. The idiographic opposition to the hegemony of the nomothetic principle, once it breaks through the looking glass and graduates into a selfconscious idiopraxis, begins to resist that hegemony, and to occupy the counterpoint position at which alone the individual can perceive social realities and imagine a telos or two into actual existence. It is one of the tasks of translation theory to spell out the link between the position of the social perceiver and the translative/ pedagogic practices that keep the traffic of perceptions committed to freshness and novelty. That commitment involves continually cleaning up the deadwood that will, if we leave it as it is, push us into morally and intellectually lazy capitulation to the state apparatus.

The classical state machine's pedagogy wants us to keep parroting what was valid yesterday, and preferably to do the same parroting over large stretches of territory to make the state's life easier; this is one of the forces pressing states to go imperial. A pedagogy 
wedded to fresh perception and originality has to therefore present itself to the individual as a counter pedagogy, pitting the individual -- and the subcommunity she roots for -- over against some state-sponsored hegemony. The point of departure for a counter pedagogy must therefore obviously be some hegemony (either vividly present or chronologically past but culturally present). To expect the public or private patrons of an educational or translative apparatus to masochistically sponsor explicit and transparent critique of their own hegemony is too starry-eyed to survive as a plan. However, those of us who nurture the hope that free and original thinking can flourish against these odds can learn how to institutionalise formal dialogue between subcommunities and make it part of the pedagogy. That way, we trick the patrons into sponsoring processes that undermine their hegemony while appearing to play a feel-good Rotarian game of the twin cities genre, except that we will tweak it into twin languages or twin musicologies or twin painting systems instead, with effects that are fatal for all hegemonies.

\section{Bongitude}

Now to get back to Bongitude. Bongs are known for their quarrelsome nature, enshrined in such shibboleths as "A city with five Bongs in it is bound to have six Durga Pujas going". You can therefore expect us to lean over backwards to do what appears maximally unclannish, to censure ourselves and praise others. The point is to exploit this. Get your young Bongs, for instance, to actually work with your Sirds to look at oral history material about the way the partition played out differently in Punjab and Bengal, educating them about the construct "Lahnda" and the rest of the story. Give older Bongs similar toys to start with. Before you can say Rosogolla, or whatever other shibboleth you're accustomed to, you will have disengaged Bongland from the unexamined and silly adoration of its ghettoised deities and put all Bongs on the longitudinal track of retrieving a sense of place for the real Bengal and its real constituents that had been rendered invisible under the culturalist regime that could see only one pure language or one pure ethnicity per freedom struggle. The moment you place interentity dialogue at the heart of the educational process and use 
actual translation as a tool in this enterprise, you are on your way to a serious truth and reconciliation telos that, given half a chance, will go far beyond its South African beginnings.

Appendix: a note on regionally displaced users of major Indian languages

1) In educational and other language-relevant policies in India, insufficient attention is paid to those middle class students who, in terms of access to equipment or resources, seem not to suffer from glaring deficits and therefore seem not to need any serious assistance from the educational system. But some middle class students, when they grow up, become makers and implementers of national policies. If they are not enabled to detect and address their own important deficits, the result is that the absence of critical scrutiny of their own situation leaves them ill-equipped to understand and address deficits in other sections of society. One serious problem with the policies that have been taken seriously by politicians and the usual commentators is that these policies completely ignore the fact that the nearexclusive focus on English in India's educational system leaves the entire middle class sadly ill-equipped to understand and conduct serious discourse in Indian languages. To expect Hindi to flourish just because some classroom time is spent on it, in a nation where neither Hindi nor the other Indian languages are being encouraged for critical and academic use, is not a viable strategy.

2) All known policy documents in India pay only lip service to mother tongue medium education. They fail to address the predicament of what I shall call 'Region-Displaced' middle class students whose mother tongue state and residential state are distinct - for example, Kannadiga students who live in Odisha. Unless Region-Displaced (RD) students are given serious resources to attain literacy in their mother tongue, their cognitive competence remains deficient. Many of us fail to notice this deficit as it is often masked by specially cultivated English skills and other social advantages. RD students, though not numerous, are a significant proportion of the vocal middle class, and often 
grow up to be influential; this decreases the chances of their deficits being publicly commented on.

3) Now, Region-Displaced students often display belowaverage levels of public awareness and socio-cultural participation. They tend to be alienated both from their mother tongue state and from their residential state. They fail to follow the local processes in either of their states -they cannot follow the news media, or understand film/ television content, or meaningfully take part in festivals. They thus become culturally disenfranchised 'nebulously all-India citizens without a home state', incapable even of casting an informed vote for this or that MLA candidate, for instance. This alienation has many side-effects that have been seriously weakening India's integrity, self-confidence and intellectual/moral health. At the end of these remarks I note that one important side-effect is a weakening of India's scientific and technological profile.

4) Insisting (for doctrinal reasons) that every Region-Displaced student must receive early schooling in the medium of his or her mother tongue, come what may, is neither feasible nor a well-thought-out response to this predicament. The system needs to offer choices. At present, RD students are forced to abandon their mother tongue and get educated either (a) entirely in English, in a private English medium school, or (b) entirely in Hindi and English, in a Kendriya Vidyalaya, or (c) entirely in the regional language of the state of residence. The present dispensation has convinced everybody that augmenting this (a)-(c) list by adding any choice (d) or (e) which involves serious cultivation of the RD students' mother tongues will overburden RD students, whereupon they will fail to compete with local students. We need to find a way out of this false sense of 'there is no choice', for otherwise we continue the destruction of the personal socio-cultural resources of RD students, who are an influential section of our middle class.

5) The way out has to include innovative use of ICT resources providing long distance audio-visual access to spoken and written pedagogic materials from the RD student's mother 
tongue state. For a child to benefit from these resources will involve synergy between online instructors based in the mother tongue state and on-the-spot facilitators who teach at the school where the child is studying. (I am visualising additional classes held by facilitating teachers at the child's school, where the teachers don't know the child's mother tongue but will expose the child to the audio-visual resources and on-line materials. Ideally the child will have video-conferencing access to a teacher located in the mother tongue state. Even in non-ideal situations where videoconferencing is unavailable, the child's assignments will have to be corrected by some teacher in the mother tongue state, and the facilitating teacher at the child's school will have to liaise with that remote teacher.) Such teachinglearning materials will have to be specially developed for RD students; note that the existing primers meant for home state users presume locally available background knowledge and therefore will be opaque to RD students.

6) How shall we find time in the curriculum to avoid overburdening RD students? There are several choices. My recommendation is that an $\mathrm{RD}$ student should be given mother tongue proficiency lessons in the niche that many proposals for educational policy reserve for Sanskrit. Other choices can be defended; the exact choice made in a particular context is not the main issue; the point is that a menu of reasonable options should be given to RD children, so that particular children can make choices best suited to their individual situations. Just as Sanskrit is sometimes proposed as a pedagogically enabling language, likewise it is essential to see that the child's mother tongue is an enabling resource which - unlike Sanskrit - is indispensable. In particular, a child who has been uprooted from his or her mother tongue never acquires full-scope cognitive proficiency, especially in science research at the level that is needed to conduct debates and win arguments when challenging a position taken by a native speaker of English. That the absence of mother tongue proficiency causes such a deficit has been shown by psycholinguistic and educational research. 
7) The interface between language education and science needs attention in the context of another problem with most policy documents. Many politicians, administrators and educationists frequently express the aspiration that India must catch up with advanced nations in science capabilities including science research. But the overall vision as it now stands in the national imagination fails to stress science education; it specifically fails to stress its importance in the context of eliminating the gender disparity (and other social disparities) in education. In this context it is important not only to recall article $51 \mathrm{~A}(\mathrm{~h})$ of our Constitution [It shall be the duty of every citizen of India - ...(h) to develop the scientific temper, humanism and the spirit of inquiry and reform] but also to note that UNESCO Director-General Irina Bokova in her 2013 vision statement has said "Gender parity means literacy. It means access to science. It means genuine possibilities for girls to become the person they want to be, to strengthen the fabric of communities and societies as a whole." [http://www.unesco.org/ new/ fileadmin/MULTIMEDIA/HQ/BPI/EPA/images/media_s ervices/Director-General/Vision2013.pdf]

8) Researchers at the language-education interface have shown that students who grow up without serious anchoring in their mother tongue - up to the level known as Cognitively Advanced Language Proficiency, CALP - are handicapped in their scientific reasoning. Unless the mother tongue tweaking of our educational policies is done along the lines I suggest above, there is no hope for a serious upswing in science education and research in India in the foreseeable future.

\section{References}

Bargohain, H. (2014). Asamiyar drishtite Bangali. (B. Das, Trans). Sandhitsa, 13(1), 68-70.

Bleich, D. (1988). The double perspective: language, literacy, and social relations. Northwestern University Press: Evanston, IL.

Dasgupta, P. (2000). The post-missionary condition: towards perceptual reciprocity. In S. Simon \& P. St-Pierre (Eds.), Changing the terms: 
translating in the Postcolonial era, (289-305). University of Ottawa Press: Ottawa.

Dasgupta, P. (2016). The theater and classical India: some availability issues. Philosophy East and West, 66(1), 60-72.

Ganguly, S. N. (1978). Rationality versus reasonableness (freedom: a reinterpretation). In J. Mohanty \& S. P. Banerjee, (Eds.)., Self, knowledge, and freedom: essays for Kalidas Bhattacharyya (31 to 70). World Press: Calcutta.

Ghosh, S. (1993). Chandomay jibon. Dey's: Kolkata.

Mills, C. W. (1959). The sociological imagination. Penguin: Harmondsworth.

Simon, S. (2006). Translating Montreal: episodes in the life of a divided city. McGill-Queen's University Press: Montreal and Kingston/ London/ Ithaca.

Vygotsky, L. (1986). Thought and language. (A. Kozulin, Trans./Ed.). MIT Press: Cambridge, MA. 